\title{
A retrospective study of electrodiagnostically evaluated ulnar neuropathies with special guidelines for ulnar neuropathies at elbow
}

\author{
Ram Lochan Yadav * (D)
}

\begin{abstract}
Background: The diagnosis of type, severity of ulnar neuropathy based on symptoms and clinical tests are unsatisfactory. This study aimed to retrospectively analyze ulnar neuropathies at different sites evaluated through electrodiagnostic studies (EDx), especially for ulnar neuropathy at elbow (UNE).

Results: Total 270 ulnar neuropathy patients' data were recruited from laboratory record over a five-year period (2016-2021).Their demographic data, clinical history and EDx parameters were analyzed focusing on etiology, nerve lesion types, 5th-digit sensory, dorsal ulnar cutaneous nerve (DUCN) conduction, motor nerve conduction velocity (NCV) across elbow along with EMG of ADM, FDI, FCU, FDP muscles. The patients grouped into traumatic injuries - 27.8\% (T) and $72.2 \%$ non-traumatic (NT) had varied sensory-motor symptoms: pain-10\%, altered sensation-28.1\%, pain-paresthesia-14.8\%, atrophy - 25.2\% and clawing-8.9\%. UNE was the most prevalent (82.75\%-NT, $66.67 \%-T)$ with $<50 \mathrm{~m} / \mathrm{s}$ motor and sensory NCV across elbow. Compound muscle action potential (CMAP) amplitude $>50 \%$ drop across elbow was seen in 55.17\%-NT and 54.16\%-T groups. Abnormal DUCN and short-segment inching NCV were less frequently noted. In EMG, ADM (T-83.33\% and NT-65.51\%) and FDI (T-70.83\% and NT-68.96\%) muscles were evaluated the most and FDP the least.

Conclusion: UNE was the most common followed by forearm and wrist. NCV and CMAP across elbow are stronger EDx parameters for UNE. Neuropathy was irrespective of gender and prevalent at early of middle age. The EDx could be considered as one of the most valuable tests in confirming the localization, severity and type of ulnar nerve lesion, which favors management and prognosis of patient.
\end{abstract}

Keywords: Ulnar nerve, Neuropathy, Electrodiagnostic studies, Nerve lesion

\section{Background}

The ulnar neuropathy is the second most common neuropathy of upper extremities after the median nerve, specifically carpal tunnel syndrome (CTS) [1]. In traumatic injuries, the ulnar nerve may be injured at any sites along its course depending on the site and nature of trauma.

*Correspondence: dr.ramlochan04@gmail.com

Department of Physiology, Chitwan Medical College, Chitwan,

Bharatpur 44200, Nepal
In non-traumatic injury, there are four common sites of ulnar nerve compressions including focal lesion at wrist, hand, elbow and less commonly at axilla. Above all, the ulnar nerve is most frequently compressed at elbow [2].

\subsection{Ulnar neuropathy at elbow (UNE)}

It occurs at four sites: (1) median intermuscular septum, (2) retroepicondylar groove, (3) humeroulnar arcade and (4) the point of exit from the flexor carpi ulnaris. Among all, the retrocondylar ulnar neuropathy is the most common [3]. The callus formation from the previous trauma 
causes over stretching of the ulnar nerve resulting ulnar nerve palsy called Tardy ulnar nerve palsy [4]. Occasionally the ulnar nerve is compressed in the cubital tunnel by ganglia, soft tissue tumor, etc. A UNE patient presents with sensory symptoms with numbness and tingling in fourth and fifth fingers and also in the ulnar border of hand and the motor defect with varying degrees of weakness ranging from clumsiness to frank paralysis [5].

Froment sign is caused by reduced strength of the adductor pollicis and FDI, with compensation made by the flexor pollicis longus. The typical ulnar griffe or claw deformity in ulnar lesions due to unopposed extensor tone at the fourth and fifth metacarpophalangeal joints and unopposed flexor tone at the interphalangeal joints. The sparing of FDP in the distal ulnar lesion produces more clawing than more proximal lesions due to greater flexion of the interphalangeal joints of the fourth and fifth digits. The palmaris brevis $(\mathrm{PB})$ sign, wrinkling of skin overlying the hypothenar eminence during 5 th digit abduction, is due to contraction of the PB which is spared with ulnar neuropathy at wrist (UNW) [3].

Wartenberg sign, abducted posture of little finger, can be one of the earliest signs of UNE is due to weakness of the third palmar interosseous. The Phalen test with applying pressure over the ulnar groove and the elbow flexion test is analogous to the carpal compression test used to elicit ulnar paresthesias. Tinel sign may be useful sometimes. However, these provocative tests have a high incidence of false positives due to mechanosensitive active nerves [6].

\subsection{Ulnar neuropathy at distal forearm}

The ulnar nerve, distal to cubital tunnel, traverses through the belly of flexor carpi ulnaris. The site of exit-the flexor pronator aponeurosis-may be a point of entrapment. The patients complain of sensory and motor phenomena localized to ulnar nerve distribution in hand [6].

\subsection{Ulnar neuropathy at wrist (UNW)}

This produces ambiguous clinical sign and symptoms, ranging from a pure sensory deficit to pure motor abnormalities, which may or may not involve the hypothenar muscles. The most common compression at wrist is of the deep palmar branch.

\subsection{Ulnar neuropathy above the elbow}

Ulnar neuropathy above elbow is usually associated with median and radial nerve involvement. In the upper arm, especially the non-traumatic ulnar nerve lesions are very rare [7].

The confirmation of the compressed area of ulnar nerve along its path is not so easy. It requires the combination of thorough clinical examinations and electrodiagnostic studies (EDx) including nerve conduction studies (NCS) and electromyography (EMG) $[8,9]$. Despite the availability of the variety of tests and different techniques of EDx, the diagnosis of ulnar neuropathy is still challenging [10].

The aim of this study was to report prevalence of ulnar neuropathies at different sites through retrospective analysis of the electrodiagnostic tests of a five-year period, further, to evaluate the specific guidelines for diagnosing ulnar neuropathy at elbow.

\section{Methods}

This was a retrospective cohort study. Out of 1500 patient records with neuropathies, 270 (18\%) patients diagnosed with ulnar neuropathies were recruited from the record database over a five-year period (2016-2021) from Clinical Physiology Lab of Department of Physiology, Chitwan Medical College, CMC, Nepal, and Arya Diagnostics, Bharatpur, Chitwan. The patient records having only ulnar mononeuropathy with mean age $39.92 \pm 10.9$ years of both sexes were included in the study, and the patients with neuropathies other than ulnar neuropathy and/or polyneuropathies and with comorbidities like diabetes and thyroid disorders causing neuropathy were excluded. The patients' demographic data including age, sex, clinical features, known cause of lesion (etiology) and electrodiagnostic (EDx) findings were noted from the record. The following electro-diagnostic findings were noted: type of injury (demyelinating vs axonal), ulnar SNAP of the fifth finger, SNAP of dorsal ulnar cutaneous nerve, accompanying injury, CMAP of ulnar nerve, nerve conduction velocities across elbow and special Edx techniques, EMG findings with effects of ulnar nerve injury on corresponding muscles. All the Edx tests performed and the medical records were noted and diagnoses for neuropathy were made by the same investigator (Principal Author of this study) at both laboratories which avoided the discrepancy in observations and records. This study included the patient's data following the standard protocol and laboratory conditions with room temperature maintained at $23 \pm 2{ }^{\circ} \mathrm{C}$ during tests.

\subsection{Ulnar sensory nerve conduction procedure}

The ulnar sensory nerve conduction was recorded from fifth and fourth digits using ring electrodes by antidromic stimulation with placing the stimulating electrode $3 \mathrm{~cm}$ proximal to the distal crease at the wrist. The antidromic conduction of the dorsal branch of ulnar nerve was measured by stimulating the ulnar nerve $5-8 \mathrm{~cm}$ proximal to the ulnar styloid process between flexor carpi ulnaris and ulna. The active recording electrode was placed between fourth and fifth metacarpals and reference electrode at 
the base of fifth digit. The recommended filter setting for sensory conduction was set at $10 \mathrm{~Hz}$ to $2 \mathrm{kHz}$, sweep speed $2 \mathrm{~ms} /$ division and gain $5 \mathrm{mV} /$ division. The signal enhancement with averaging was kept for 2000 times. Onset latency, SNAP amplitude, SNAP duration and sensory nerve conduction velocity (SNCV) were recorded for analysis.

\subsection{Ulnar motor nerve conduction procedure and laboratory protocol for ulnar neuropathy at different sites}

Ulnar nerve is relatively superficial along its course; therefore, motor nerve conduction velocity (MNCV) of various segments measured by stimulating Erb's point, axilla, elbow, wrist and palm. Recording was made from central belly of ADM and FDI. For the electrophysiological evaluation of ulnar neuropathy at elbow, the ulnar MNCV was recorded from ADM and stimulation of the ulnar nerve at (1) wrist: $3 \mathrm{~cm}$ proximal to the distal crease; (2) below elbow: $3-4 \mathrm{~cm}$ distal to medial epicondyle; (3) above elbow: $5-8 \mathrm{~cm}$ proximal to the medial epicondyle; (4) axilla; and (5) Erb's point. The onset latency and the base-to-peak amplitude of CMAP were measured. The limb position during stimulation and distance measurement was kept with $90^{\circ}$ flexion of elbow and forearm was supinated with extended wrist. Ulnar NCV across the elbow segment if $<50 \mathrm{~m} / \mathrm{s}$ was considered abnormal. Moreover, slowing of motor conduction by $>11 \mathrm{~m} / \mathrm{s}$ across elbow compared to forearm segment considered significant. Further, secondary criteria for localization of ulnar neuropathy employed were reduction in CMAP amplitude across elbow. Fall in amplitude across elbow more than $50 \%$ or area reduction more than $40 \%$ with dispersion was considered UNE. A $20 \%$ fall in CMAP amplitude across elbow with stimulation at distance $10 \mathrm{~cm}$ difference was considered focal demyelination [10-12].

The inching method employed short segment of 1 or $2 \mathrm{~cm}$ showing a point of abrupt change in latency or amplitude for focal localization of the involved segment [12-14]. Similar to ulnar MNCV across elbow, antidromic ulnar sensory study was carried out from fifth digit by stimulating from different sites along nerve course and onset latency and SNAP amplitudes and SNCV were measured. SNCV below $50 \mathrm{~m} / \mathrm{s}$ across elbow and reduction in base-to-peak amplitude by $43 \%$ or $>8 \mu \mathrm{V}$ were considered abnormal $[12,15]$.

\subsection{Muscles selected for electromyography (EMG)}

EMG further aided in localization of ulnar neuropathy, chronicity, severity, degree of axonal degeneration and further differentiates from brachial plexopathy, C8-T1 radiculopathy and UNW. EMG included ADM, FDI,
FCU, FDP and APB muscles. Mild lesions with sensory loss revealed normal EMG. Sharp waves and fibrillation along with clinically appreciated atrophy suggests axonal degeneration.

Ulnar neuropathy at distal forearm: In case of ulnar neuropathy at distal forearm, the patient usually complained of motor and sensory defect localized to ulnar distribution in hand. MNCV revealed normal to marginally affected but abnormal NCS to dorsal cutaneous branch of ulnar nerve. Short-segment inching technique from wrist to medial epicondyle (ME) demonstrated the conduction block at the site of lesion [15].

Ulnar neuropathy at wrist (UNW): UNW evaluated with electrodiagnostic findings along with clinical features. Shea and McClain classified ulnar compression syndromes of the wrist and hand into 3 types. In type I, the lesion is proximal to or within Guyon canal, involves both the superficial and deep branches and causes a mixed motor and sensory deficit, with weakness involving all the ulnar hand muscles.

In type II, the lesion is within Guyon canal or at the pisohamate hiatus, involves the deep branch and causes a pure motor deficit with a variable pattern of weakness depending on the precise site of compression.

A type III lesion is in Guyon canal or in the palmaris brevis, involves the superficial branch only and causes a purely sensory deficit. In the type I and III lesions, sensory loss should spare the dorsum of the hand, innervated by the DUC branch and should also largely spare the hypothenar eminence because its innervation is via the palmar cutaneous branch, which arises proximal to the wrist [6].

UNW evaluated from ulnar motor NCS recording from ADM and FDI, sensory conduction study from superficial and dorsal branch. Median motor and sensory conduction study were done to exclude the involvement of other nerves. Delayed distal motor latency usually more than $3.4 \mathrm{~ms}$ to ADM and $4.5 \mathrm{~ms}$ to FDI considered abnormal conduction across wrist. Similarly, normal CMAP amplitude for ADM and FDI was $5 \mathrm{mV}$ and $6 \mathrm{mV}$, respectively. EMG of ADM, FDI and muscles of forearm (FCU, FDP) also put a clue to probable site of lesion [6].

The grading for the severity of ulnar neuropathy was based on the clinical features and electrodiagnostic findings. Patients with mild pain, paresthesia and abnormal ulnar sensory conduction parameters graded as mild neuropathy; pain, paresthesia, abnormal ulnar sensory and motor conduction parameters and neuropathic EMG of the related muscles graded as moderate; and paresthesia, muscle weakness, clawing/atrophy, complete absence or highly affected motor and sensory nerve conduction studies and chronic 
Table 1 Patient characteristics $(N=270)$

\begin{tabular}{lll}
\hline Patient characteristics & Group & N (\%) \\
\hline Sex & Male (M) & $180(66.7 \%)$ \\
& Female (F) & $90(33.3 \%)$ \\
Affected side & Right & $160(59.3 \%)$ \\
& Left & $95(35.2 \%)$ \\
Etiology & Bilateral & $15(5.6 \%)$ \\
& Traumatic & $75(27.8 \%)($ Male-47\%, \\
& & Female-53\%) \\
Severity & Non-traumatic & $195(72.2 \%)($ Male-53\%, \\
& & Female-47\%) \\
& Mild & $179(66.3 \%)$ \\
& Moderate & $55(20.4 \%)$ \\
& Severe & $36(13.3 \%)$
\end{tabular}

Table 2 Patient's major complaints $(N=270)$

\begin{tabular}{ll}
\hline Symptoms & $\boldsymbol{N}$ (\%) \\
\hline Pain & $27(10 \%)$ \\
Sensory defect & $76(28.1 \%)$ \\
Pain and sensory & $40(14.8 \%)$ \\
Motor defect & $26(9.6 \%)$ \\
Motor and wasting & $68(25.2 \%)$ \\
Motor and wasting with clawing & $24(8.9 \%)$ \\
Unknown (Non-symptomatic) & $9(3.3 \%)$ \\
\hline
\end{tabular}

neuropathic EMG of the related muscles graded as severe neuropathy.

\subsection{Ethical consideration}

The data of the research have been employed from hospital records of patients who have signed and stated their consent for using their not-identifying data for the aim of research. This study was conducted according to the guidelines of the Declaration of Helsinki, and approval was taken by the Institutional Ethics Review Committee, Chitwan Medical College, CMC, Nepal.

\subsection{Statistical analysis}

The SPSS (version 21; IBM Corporation, Armonk, NY, USA) was used for data analysis. The descriptive tests were applied for all the study variables.

\section{Results}

Total 270 cases with mean age $39.92 \pm 10.9$ years diagnosed as ulnar mono-neuropathy were grouped into two main categories based on etiology as $27.8 \%$ nerve damage was due to Traumatic injuries $(\mathrm{T})$ and $72.2 \%$ non-traumatic (NT) types (Table 1 ).
Table 3 Neuropathy types

\begin{tabular}{lcc}
\hline Neuropathy types & Traumatic (75) & Non-traumatic (195) \\
\hline Demyelinating & $8(10.6 \%)$ & $125(64.10 \%)$ \\
Axonal & $45(60 \%)$ & $48(24.61 \%)$ \\
Mixed & $22(29.33 \%)$ & $22(11.28 \%)$ \\
\hline
\end{tabular}

Table 4 Severity within different etiology

\begin{tabular}{lll}
\hline Severity & Traumatic (75) & Non-traumatic (195) \\
\hline Mild & $20(26.67 \%)$ & $134(68.71 \%)$ \\
Moderate & $45(60 \%)$ & $35(17.94 \%)$ \\
Severe & $10(13.33 \%)$ & $26(13.33 \%)$ \\
\hline
\end{tabular}

Many presented with tingling and altered sensation along with pain. On clinical examination, sensory defect, pain and altered sensation with pain were present in $28.1 \%, 10 \%$ and $14.8 \%$, respectively (Table 2 ). A significant number of patients were presented with motor abnormalities as weakness and difficulty during griping the object and decease in size of hypothenar muscle (wasting) along with difficulty in extension of 4th and 5th digits (clawing). On clinical examination, patients with mild motor defect (9.6\%), motor abnormalities along with mild wasting of hypothenar muscles $(25.2 \%)$ and wasting along with clawing of 4 th and 5 th digits $(8.9 \%)$ were noted (Table 2). However, there were not clear symptoms in $3.3 \%$ patients on clinical examination. The mean duration of symptoms was $9.83 \pm 6.77$ months ( 1 to 28 months). Of 270 cases, $66.7 \%$ and $33.3 \%$ were male and female patients. The most prevalent affected side accounted for $59.3 \%$, was in right, $35.2 \%$ in left and $5.6 \%$ with bilateral involvement (Table 1).

In traumatic injuries, axonal neuropathy was most prevalent with $60 \%$ involvement, whereas the demyelinating type was highest $(64.10 \%)$ in non-traumatic etiology (Table 3). However, involvement of both axonal and focal demyelination (mixed type) was quite more in traumatic $(29.33 \%)$ than in non-traumatic (11.28\%) group. The severity of neurological involvement and symptoms was mild in $66.3 \%$, moderate in $20.4 \% \%$ and severe in $13.3 \%$ cases (Table 1). The moderate/severe involvement was more prevalent in cases with traumatic injuries (Table 4).

The site of lesion depicted in Table 5 and Fig. 1 revealed the highest prevalence- $74.35 \%$ of UNE in non-traumatic patients. The most common sites of involvement of ulnar nerve in traumatic injuries were forearm $-40 \%$ and elbow-32\% (Fig. 2). The prevalence 
Table 5 Sites of lesion diagnosed

\begin{tabular}{lcc}
\hline Sites of lesion & Traumatic (75) & Non-traumatic (195) \\
\hline Axilla & $2(2.67 \%)$ & $0(0 \%)$ \\
Arm & $7(9.33 \%)$ & $6(3.07 \%)$ \\
Elbow & $24(32 \%)$ & $145(74.35 \%)$ \\
Forearm & $30(40 \%)$ & $14(7.17 \%)$ \\
Wrist-Guyon type 1 & $6(8 \%)$ & $4(2.05 \%)$ \\
Wrist-Guyon type 2 & $2(2.67 \%)$ & $4(2.05 \%)$ \\
Wrist-Guyon type 3 & $2(2.67 \%)$ & $12(6.15 \%)$ \\
Not clear & $2(2.67 \%)$ & $10(5.12 \%)$ \\
\hline
\end{tabular}

of ulnar nerve injuries at wrist due to trauma was $8 \%-$ Guyon type 1, 2.67\%-Guyon type 2 and 2.67\%-Guyon type 3 (Table 5 ).

Table 6 and Fig. 3 represent the electrodiagnostic evaluation of ulnar neuropathy at elbow accounting $82.75 \%$ in non-traumatic group and $66.67 \%$ in traumatic group had abnormal ulnar motor nerve conduction velocity (NCV) across elbow including $\mathrm{NCV}<50 \mathrm{~m} / \mathrm{s}$ and complete conduction block. Likewise, sensory nerve conduction velocity (SNCV) was below $50 \mathrm{~m} / \mathrm{s}$ across elbow in $68.96 \%$ non-traumatic and $58.33 \%$ traumatic patients. The compound muscle action potential (CMAP) amplitude $>50 \%$ drop across elbow was seen in $55.17 \%$ in non-traumatic and $54.16 \%$ in traumatic ulnar neuropathies. Abnormal dorsal ulnar cutaneous nerve (DUCN) SNAP and conduction velocity accounted for $41.37 \%$ in non-traumatic and $12.5 \%$ in traumatic cases.
On needle EMG evaluation (Table 7), ADM and FDI were the most frequently evaluated and FDP the least. In cases with UNE, ADM was the highly involved muscle (Traumatic-83.33\% and Non-traumatic-65.51\%); followed by FDI $(70.83 \%$ in traumatic and $68.96 \%$ in nontraumatic) and least with FDP (37.5\% in traumatic and $34.48 \%)$.

\section{Discussion}

This retrospective study evaluated 270 cases, mean age $39.92 \pm 10.9$ years, of ulnar neuropathies diagnosis made by EDx tests and techniques employed for UNE. They were presented with several symptoms with mean duration $9.83 \pm 6.77$ months. It was reported in line of this study that the most of the ulnar neuropathies encountered with a highest prevalence in those in the age group 40-49 [16].

The most prevalent symptoms were tingling sensation, numbness and paresthesia (sensory defect-28.1\%) along the ulnar border of hand and in the 5 th digit followed by weakness and slight atrophy (motor and wasting-25.2\%) of hypothenar muscle (abductor digiti minimi, ADM) (Table 2). Similar features were noted with other studies $[17,18]$. Findings with frequent atrophy of ADM and FDI were comparable to findings of Stewart mentioned atrophy of ADM (76\%) and FDI (84\%) [19].

Based on etiology, this study revealed high prevalence (72.2\%) of non-traumatic ulnar neuropathies, whereas $27.8 \%$ in traumatic injuries. Many studies illustrated the long anatomical course of ulnar nerve in hand and normal movement of hand produced possibilities of

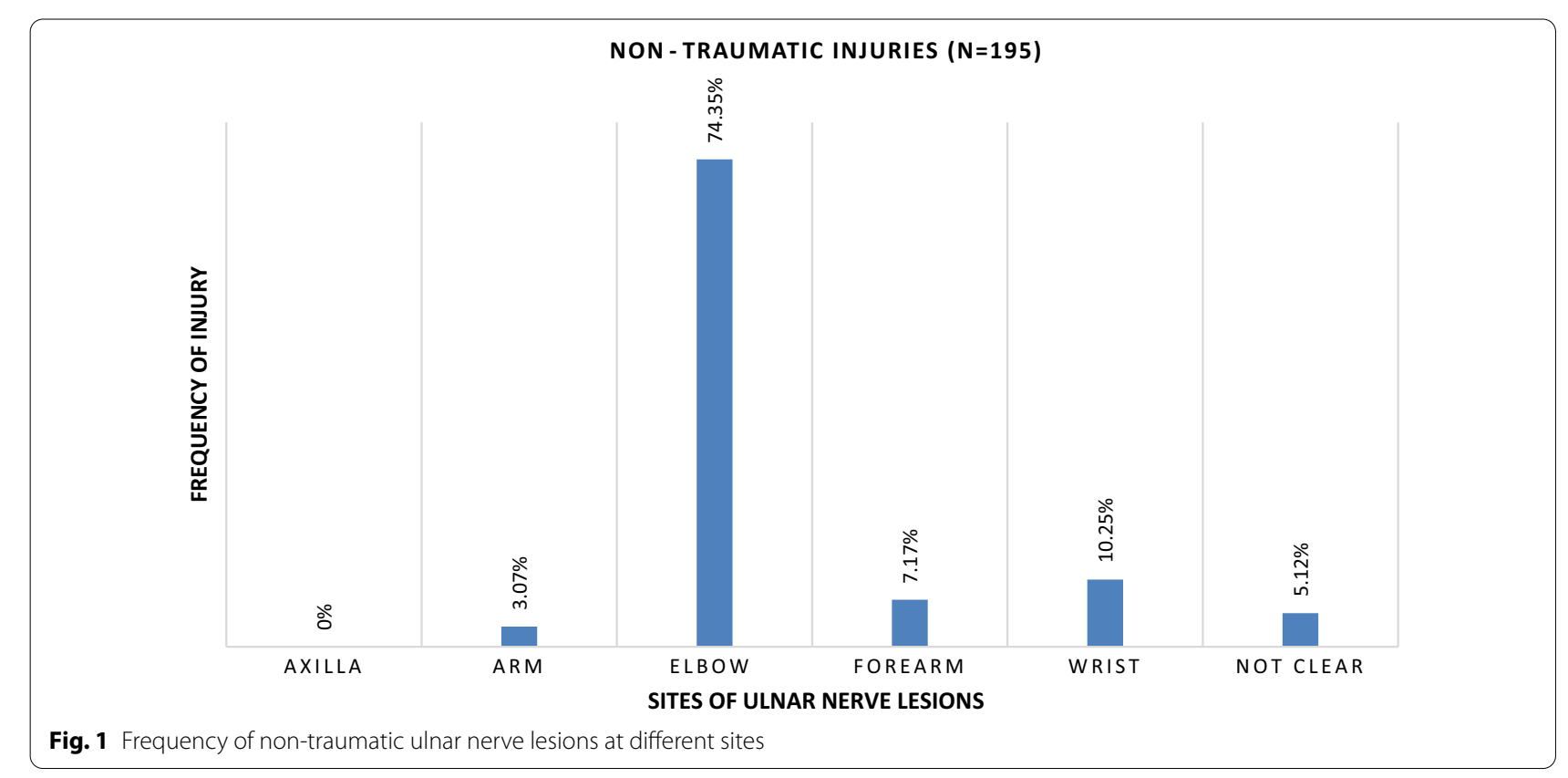




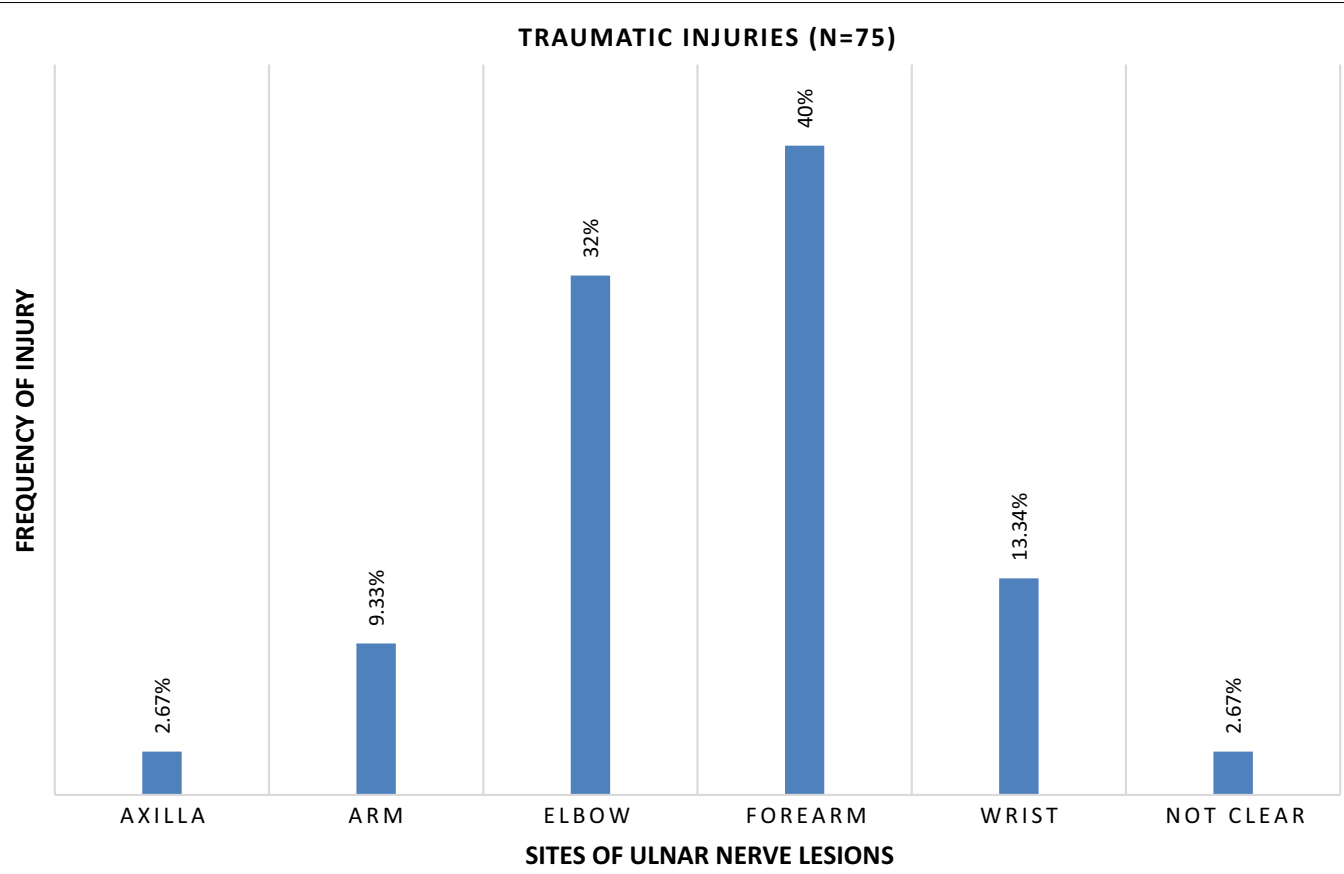

Fig. 2 Frequency of traumatic ulnar nerve lesions at different sites

Table 6 NCS findings in ulnar neuropathy at elbow

\begin{tabular}{|c|c|c|}
\hline Parameters & Etiology & Abnormal \\
\hline \multirow[t]{2}{*}{ Ulnar motor nerve conduction velocity across elbow $<50 \mathrm{~m} / \mathrm{s}$} & $\mathrm{T}$ & $16(66.67 \%)$ \\
\hline & NT & $120(82.75 \%)$ \\
\hline \multirow[t]{2}{*}{ motor conduction velocity difference between forearm and elbow segment $>11 \mathrm{~m} / \mathrm{s}$} & $\mathrm{T}$ & $15(62.5 \%)$ \\
\hline & NT & $98(67.58)$ \\
\hline \multirow[t]{2}{*}{ CMAP amplitude $>50 \%$ drop across elbow } & $\mathrm{T}$ & $13(54.16 \%)$ \\
\hline & NT & $80(55.17 \%)$ \\
\hline \multirow[t]{2}{*}{ CMAP amplitude $>20 \%$ drop across elbow at $10 \mathrm{~cm}$ difference } & $\mathrm{T}$ & $10(41.67 \%)$ \\
\hline & NT & $80(55.17)$ \\
\hline \multirow{2}{*}{$\begin{array}{l}\text { Inching technique: > 10\% CMAP amplitude drop and/or abrupt shift in latency by } 8 \mathrm{~cm} \text { on Short-seg- } \\
\text { ment }(2 \mathrm{~cm}) \text { stimulations }\end{array}$} & $\mathrm{T}$ & $6(24 \%)$ \\
\hline & NT & $50(34.48 \%)$ \\
\hline \multirow[t]{2}{*}{ SNCV below $50 \mathrm{~m} / \mathrm{s}$ across elbow } & $\mathrm{T}$ & $14(58.33 \%)$ \\
\hline & NT & $100(68.96 \%)$ \\
\hline \multirow[t]{2}{*}{ reduction in SNAP base-to-peak amplitude by $43 \%$ or $>8 \mu \mathrm{V}$} & $\mathrm{T}$ & $4(16.7 \%)$ \\
\hline & NT & $70(48.27 \%)$ \\
\hline \multirow[t]{2}{*}{ Abnormal Dorsal ulnar cutaneous nerve (DUCN) SNAP and conduction velocity } & $\mathrm{T}$ & $3(12.5 \%)$ \\
\hline & NT & $60(41.37 \%)$ \\
\hline
\end{tabular}

ulnar nerve damage even in absence of external traumatic injuries [20,21]. Right hand was predominantly affected-59.3\%; however, the involvement of left side was quite high too. This could be due to the reason most of the people are right handed and use it more in work than to left hand. In contrast to this study, Omejec G [10] reported the left side as a high prevalence of affected side.
Raeissadat SA et al. [22] did not find much difference between the affected sides.

Traumatic and non-traumatic injuries were comparable between male and female gender. In contrast to this, both non-traumatic (NT) and traumatic injuries (T) were more common among men than women in previous studies $[23,24]$. 
Frequently affected electrodiagnostic parameters in UNE ( $N=195)$

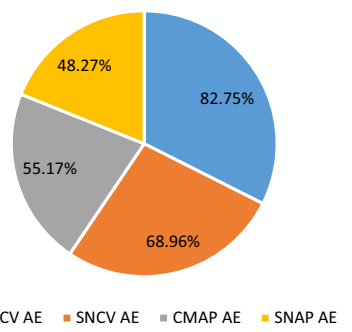

Fig. 3 Frequency of affected electrodiagnostic parameters in diagnosing ulnar neuropathy at elbow (UNE)

Table 7 EMG findings of the muscles tested routinely in case of ulnar neuropathy at elbow

\begin{tabular}{llc}
\hline Tested muscles & Etiology & Abnormal \\
\hline ADM & T & $20(83.33 \%)$ \\
FDI & NT & $95(65.51 \%)$ \\
& T & $17(70.83 \%)$ \\
FCU & NT & $100(68.96 \%)$ \\
& T & $12(50 \%)$ \\
FDP & NT & $56(38.62 \%)$ \\
& T & $9(37.5 \%)$ \\
APB & NT & $50(34.48 \%)$ \\
\hline
\end{tabular}

The types of lesion were classified as axonal, demyelinating and mixed types. In traumatic injuries, axonal neuropathy was most prevalent with $60 \%$ involvement, whereas the demyelinating type was highest (64.10\%) in non-traumatic etiology (Table 3). Similarly, involvement of both axonal and focal demyelination (mixed type) was quite more in traumatic (29.33\%) than in nontraumatic (11.28\%) group. These could be due to larger extent of damage of ulnar nerves and the relatively more duration of lesion in traumatic injuries than that of nontraumatic type. These findings are quite explainable with the understandings of mechanism and progression of neuropathy. In acute conditions, symptoms usually are position dependent due to transient dynamic ischemia and resolve simply by adjustment of posture or minor exercise restoring the blood flow to nerve. In such condition, electro-diagnostic findings are normal. As the insult to nerve continues with prolonged ischemia, it affects the myelination of ulnar nerve resulting demyelinating type of neuropathy. This could be explained in this study with most of the cases were of moderate duration (5-6 months) of continued compression or other etiology leading to demyelinating neuropathy which electrodiagnostically reflects with slowed NCV to fastest conducting nerve fibers. Moreover, the symptoms become more persistent and less intermittent, and this draws the attention of the patient to visit the doctor. Finally, if the etiology is not removed, the long-standing pathology or severe compression will lead to axonal loss referred as axonal neuropathy where motor defect and muscle atrophy are quite evident. Reduction in CMAP and SNAP amplitudes, abnormal needle EMG with altered insertional activity (due to muscle denervation), fibrillations (due to motor axon loss and denervation) and decreased recruitment or reinnervation recruitment are the features of axonal neuropathy [25-27].

The severity of neurological involvement was mild in $26.67 \%$, moderate in $60 \%$ and severe in $13.33 \%$ traumatic cases (Table 4). The moderate/severe involvement was more prevalent in cases with traumatic injuries. This could be explained from above discussion with extent and duration of nerve damage producing various degrees of clinical features. These findings were comparable with the previous report; however, prevalence of severe cases (40\%) was relatively higher than the present study [22]. In non-traumatic group, mild $(92.41 \%)$ and moderate $(24.13 \%)$ involvement was most predominant which is in line with the report of Raeissadat SA et al. [22].

The most commendable part of EDx is in predicting the sites of lesion along the course of ulnar nerve. Similar to previous report [28, 29], this study revealed the highest prevalence- $74.35 \%$ of UNE especially in nontraumatic patients. The reason for the frequent involvement of ulnar nerve at elbow could be due to its long anatomical course and rise in compressive force on ulnar at elbow flexion. In elbow extension, the medial epicondyle and OP approaches each other with slacking the HUA and loosening the nerve in the groove. With elbow flexion, the OP moves forward and away from the ME. The humeral head of the FCU, attached to the ME, and the ulnar head, attached to the OP, are pulled apart, progressively tightening the HUA across the nerve, resulting in pressure increases up $19 \mathrm{~mm} \mathrm{Hg}$ in the ulnar groove. Therefore, the ulnar nerve is vulnerable to injury following repeated minor pressure [30].

The most common sites of involvement of ulnar nerve in traumatic injuries were forearm-40\% and elbow$32 \%$. In RTA and other accidents, any part of the body may be injured depending on the site of impact and fall. However, in upper limb usually forearm, elbow, wrist and shoulder are more vulnerable to get injured [31]. Ulnar nerve damage is the most frequently encountered injury in upper limb trauma often caused by road traffic accidents [32].

The prevalence of UNW due to trauma was $8 \%-$ Guyon type 1, 2.67\%-Guyon type 2 and 2.67\%-Guyon type 3 (Table 5 ). Guyon canal syndrome is a relatively 
rare peripheral ulnar neuropathy that involves injury to the distal portion of the ulnar nerve as it travels through a narrow anatomic corridor at the wrist. Unfortunately, the incidence and prevalence of Guyon canal syndrome in the general population have not yet been accurately estimated due to the lack of studies [25]. However, Raeissadat SA et al. [22] reported a relatively higher prevalence-11\% of Guyon type 1 ulnar neuropathy caused by trauma. Likewise, they also mentioned Guyon type 3 ulnar neuropathy being the most common among nontraumatic ulnar neuropathies at wrist which is comparable to the present study.

As far as concern with the ulnar neuropathies at different sites in traumatic and especially non-traumatic types, UNE was the most prevalent; this was proven and supported by several studies [33]. Diversity of techniques was employed in different studies to reach the diagnosis. In our setup, as described in Methods section, a set of techniques were employed to make the diagnosis of UNE. However, slowing motor and sensory ulnar NCV across elbow, reduced CMAP amplitudes at elbow by $>50 \%$, MNCV difference between forearm and elbow segment $>11 \mathrm{~m} / \mathrm{s}$, were most frequently observed both in traumatic and non-traumatic UNE. Similar to this study, in Kern's research and other studies, the most reliable finding in UNE was slowing of NCV and decreased CMAP across elbow [34].

The study of DUCN is very less reliable in localization of ulnar nerve lesions at the elbow. This finding is quite in coherent with result showing the limitations of DUCN sensory response in patients with UNE [35].

Like some previous reports [10, 36] needle EMG revealed with abnormal findings in ADM (traumatic-83.33\% and non-traumatic-65.51\%) and FDI (70.83\% in traumatic and $68.96 \%$ in non-traumatic) followed by FCU but least with the FDP.

EMG characteristics-abnormal insertional activity, the spontaneous activity, abnormal MUAPs and recruitment phase-were quite helpful in grading the severity of the lesion with mild, moderate and severe form.

Thus, compared to previous studies, this study is highly suggestive for a meticulous analysis of motor and sensory nerve conduction parameters across elbow and its comparison with NCS values obtained at wrist and above elbow.

\section{Conclusion}

Ulnar nerve might get affected at various sites with varies degrees of severity along its long anatomical path due to traumatic/non-traumatic etiology. This study suggests the most common site for ulnar neuropathy is the elbow followed by forearm and wrist. Neuropathy could be irrespective of gender and more prevalent in early of middle age. The very cautious examination of slowing of ulnar motor and sensory nerves conduction across elbow and reduction in ulnar motor CMAP amplitude on stimulation above the elbow had high value in predicting the ulnar neuropathy at elbow. The electrodiagnostic (NCS and EMG) evaluation could be considered as one of the most valuable tests, especially nerve conduction across elbow, in confirming the localization, severity and type of injury at ulnar nerve, which certainly help the management and further prognosis of ulnar neuropathy. This study recommends that there must have a comprehensive and clear step-wise electrodiagnostic guideline along with patients's history and clinical examination format for the accurate diagnosis of ulnar neuropathy at different sites.

\section{Abbreviations}

CTS: Carpal tunnel syndrome; EDx: Electrodiagnostic studies; NCS: Nerve conduction study; UNE: UInar neuropathy at elbow (UNE); UNW: UInar neuropathy at wrist; DUCN: Dorsal ulnar cutaneous nerve; NCV: Nerve conduction velocity; SNCV: Sensory nerve conduction velocity; MNCV: Motor nerve conduction velocity; EMG: Electromyography; ADM: Adductor digiti minimi; FDI: First dorsal interossei; FCU: Flexor carpi ulnaris; FDP: Flexor digitorum profundus; T: Traumatic injury; NT: Non-traumatic injury; CMAP: Compound muscle action potential; SNAP: Sensory nerve action potential.

\section{Acknowledgements}

I acknowledge the IRC, CMC for providing the ethical clearance for the study.

\section{Authors' contributions}

I am the sole author and contributor for this work.

\section{Funding}

This research received no specific grant from any funding agency in the public, commercial or not-for-profit sectors.

Availability of data and materials

The data generated or analyzed are included in this article.

\section{Declarations}

Ethics approval and consent to participate

The ethical approval (Ref: CMC-IRC/077/078-019) for this retrospective study was obtained from Chitwan Medical College, Institutional Review Committee (CMC-IRC), Nepal. A written informed consent was taken from each subject before the participation in this study.

Consent for publication

Not applicable.

Competing interests

No any conflicts of interest.

Received: 1 October 2021 Accepted: 10 February 2022

Published online: 03 March 2022

\section{References}

1. Kandil MR, Darwish ES, Khedr EM, Sabry MM, Abdulah MA (2012) A community-based epidemiological study of peripheral neuropathies in Assiut. Egypt Neurol Res 34:960-966. https://doi.org/10.1179/17431 32812Y.0000000099 
2. Bouche P (2013) Compression and entrapment neuropathies. Handb Clin Neurol 115:311-366. https://doi.org/10.1016/B978-0-444-52902-2. 00019-9

3. Caliandro P, La Torre G, Padua R, Giannini F, Padua L (2016) Treatment for ulnar neuropathy at the elbow. Cochrane Database Syst Rev 11(11):CD006839. https://doi.org/10.1002/14651858.CD006839.pub4

4. Rubin G, Orbach H, Bor N, Rozen N (2019) Tardy ulnar nerve palsy. J Am Acad Orthop Surg 27(19):717-725. https://doi.org/10.5435/ JAAOS-D-18-00138

5. Waugh RP, Pellegrini VD Jr (2007) Ulnar tunnel syndrome. Hand Clin 23(3):301-310. https://doi.org/10.1016/j.hcl.2007.06.006

6. Shea JD, McClain EJ (1969) Ulnar nerve compression syndrome at and below the wrist. J Bone Joint Surg Am 51:1095-1103

7. Nakajima M, Ono N, Kojima T et al (2009) Ulnar entrapment neuropathy along the medial intermuscular septum in the midarm. Muscle Nerve 39:707-710

8. Thibault MW, Robinson LR, Franklin G, Fulton-Kehoe D (2005) Use of the AAEM guidelines in electrodiagnosis of ulnar neuropathy at the elbow. Am J Phys Med Rehabil 84(4):267-273. https://doi.org/10.1097/01.PHM. 0000156893.12433.C7

9. Kitzinger H, Aszmann O, Moser V, Frey M (2005) Significance of electroneurographic parameters in the diagnosis of chronic neuropathy of the ulnar nerve at the elbow. Handchir Mikrochir Plast Chir 37(4):276-281

10. Omejec G, Podnar S (2016) Proposal for electrodiagnostic evaluation of patients with suspected ulnar neuropathy at the elbow. Clin Neurophysiol 127(4):1961-1967. https://doi.org/10.1016/j.clinph.2016.01.011

11. American Association of Electrodiagnostic Medicine, Campbell WW (1999) Guidelines in electrodiagnostic medicine. Practice parameter for electrodiagnostic studies in ulnar neuropathy at the elbow. Muscle Nerve 8:S171-205

12. Azrieli Y, Weimer L, Lovelace R, Gooch C (2003) The utility of segmental nerve conduction studies in ulnar mononeuropathy at the elbow. Muscle Nerve 27(1):46-50. https://doi.org/10.1002/mus.10293

13. Stewart JD (2000) Focal peripheral neuropathies, 3rd edn. Lippincott Williams Wilkins, Philadelphia, p 580

14. Lo YL, Leoh TH, Xu LQ et al (2005) Short-segment nerve conduction studies in the localization of ulnar neuropathy of the elbow: use of flexor carpi ulnaris recordings. Muscle Nerve 31:633-636. https://doi.org/10.1002/ mus.20250

15. Practice parameter for electrodiagnostic studies in ulnar neuropathy at the elbow: summary statement (1999) American Association of Electrodiagnostic Medicine, American Academy of Neurology, American Academy of Physical Medicine and Rehabilitation. Muscle Nerve 22(3):408-11. https://doi.org/10.1002/(sici)1097-4598(199903)22:3<408:.aid-mus16>3.0. co;2-7

16. Roquelaure $Y, H a C$, Leclerc $A$, Touranchet $A$, Sauteron M, Melchior M, Imbernon E, Goldberg M (2006) Epidemiologic surveillance of upperextremity musculoskeletal disorders in the working population. Arthritis Rheum 55(5):765-778. https://doi.org/10.1002/art.22222

17. Dy CJ, Mackinnon SE (2016) Ulnar neuropathy: evaluation and management. Curr Rev Musculoskelet Med 9(2):178-184. https://doi.org/10.1007/ s12178-016-9327-x

18. Calfee RP, Manske PR, Gelberman RH, Van Steyn MO, Steffen J, Goldfarb CA (2010) Clinical assessment of the ulnar nerve at the elbow: reliability of instability testing and the association of hypermobility with clinical symptoms. J Bone Joint Surg Am 92(17):2801-2808. https://doi.org/10. 2106/JBJS.J.00097

19. Stewart JD (1987) The variable clinical manifestations of ulnar neuropathies at the elbow. J Neurol Neurosurg Psychiatry 50(3):252-258. https:// doi.org/10.1136/jnnp.50.3.252

20. Robertson C, Saratsiotis J (2005) A review of compressive ulnar neuropathy at the elbow. J Manipulative Physiol Ther 28(5):345. https://doi.org/10. 1016/j.jmpt.2005.04.005

21. Khedr EM, Fawi G, Allah Abbas MA, El-Fetoh NA, Zaki AF, Gamea A (2016) Prevalence of common types of compression neuropathies in Qena Governorate/Egypt: a population-based survey. Neuroepidemiology 46(4):253-260. https://doi.org/10.1159/000444641

22. Raeissadat SA, Youseffam P, Bagherzadeh L, Rayegani SM, Bahrami MH, Eliaspour D (2019) Electrodiagnostic findings in 441 patients with ulnar neuropathy - a retrospective study. Orthop Res Rev 11:191-198. https:// doi.org/10.2147/ORR.S230116
23. Kouyoumdjian JA, Graça CR, Ferreira VF (2017) Peripheral nerve injuries: a retrospective survey of 1124 cases. Neurol India 65(3):551. https://doi.org/ 10.4103/neuroindia.NI_987_16

24. Eser F, Aktekin LA, Bodur $\mathrm{H}, \bar{A} \tan \mathrm{C}$ (2009) Etiological factors of traumatic peripheral nerve injuries. Neurol India 57(4):434-437. https://doi.org/10. 4103/0028-3886.55614

25. Maki Y, Firrell JC, Breidenbach WC (1997) Blood flow in mobilized nerves: results in a rabbit sciatic nerve model. Plast Reconstr Surg 100:627-633

26. Nakamura K, Uchiyama S, Ido Y, Itsubo T, Hayashi M, Murakami H et al (2014) The effect of vascular pedicle preservation on blood flow and clinical outcome following ulnar nerve transposition. J Hand Surg 39:291-302

27. Menorca RM, Fussell TS, Elfar JC (2013) Nerve physiology: mechanisms of injury and recovery. Hand Clin 29(3):317-330. https://doi.org/10.1016/j. hcl.2013.04.002

28. Eliaspour D, Sedighipour L, Hedayati-Moghaddam MR, Rayegani SM, Bahrami MH, Roghani RS (2012) The pattern of muscle involvement in ulnar neuropathy at the elbow. Neurol India 60(1):36. https://doi.org/10. 4103/0028-3886.93586

29. Balikova M, Neklanova M, Sulla I et al (2017) Bilateral position-related ulnar neuropathy at elbow in pediatric population and review of the literature. Childs Nerv Syst 33:399-405. https://doi.org/10.1007/ s00381-017-3347-8

30. Werner CO, Ohlin P, Elmqvist D (1985) Pressures recorded in ulnar neuropathy. Acta Orthop Scand 56(5):404-406. https://doi.org/10.3109/ 17453678508994358

31. Karkee R, Lee AH (2016) Epidemiology of road traffic injuries in Nepal, 2001-2013: systematic review and secondary data analysis. BMJ Open 6:e010757. https://doi.org/10.1136/bmjopen-2015-010757

32. Ramage JL, Varacallo M (2021) Anatomy, shoulder and upper limb, hand guyon canal. [Updated 2020 Sep 8]. In: StatPearls. StatPearls Publishing, Treasure Island (FL). https://www.ncbi.nlm.nih.gov/books/NBK534814/

33. Landau ME, William W (2013) Campbell, clinical features and electrodiagnosis of ulnar neuropathies. Phys Med Rehabil Clin North Am 24:49-66. https://doi.org/10.1016/j.pmr.2012.08.019

34. Bains S, Rocha Cabrero F (2021) Electrodiagnostic evaluation of ulnar neuropathy. In: StatPearls. StatPearls Publishing, Treasure Island (FL). https://www.ncbi.nlm.nih.gov/books/NBK564408/

35. Venkatesh S, Kothari MJ, Preston DC (1995) The limitations of the dorsal ulnar cutaneous sensory response in patients with ulnar neuropathy at the elbow. Muscle Nerve 18(3):345-347. https://doi.org/10.1002/mus. 880180314

36. Kurver A, Smolders J, Verhagen WIM, Meulstee J, Nijhuis FAP (2019) The diagnostic sensitivity for ulnar neuropathy at the elbow is not increased by addition of needle EMG of ADM and FDI when nerve conduction studies are normal. Front Neurol 10:196. https://doi.org/10.3389/fneur. 2019.00196

\section{Publisher's Note}

Springer Nature remains neutral with regard to jurisdictional claims in published maps and institutional affiliations.

\section{Submit your manuscript to a SpringerOpen ${ }^{\circledR}$ journal and benefit from:}

- Convenient online submission

Rigorous peer review

- Open access: articles freely available online

- High visibility within the field

Retaining the copyright to your article

Submit your next manuscript at springeropen.com 